\section{Australian Journal of \\ Crop Science}

\title{
Anthocyanin content, total phenolic content, and antiradical capacity in different ear components of purple waxy corn at two maturation stages
}

\author{
Sakunkan Simla ${ }^{1, *}$, Surasak Boontang ${ }^{1}$, Bhornchai Harakotr ${ }^{2}$ \\ ${ }^{1}$ Department of Agricultural Technology, Faculty of Technology, Mahasarakam University, Maha Sarakam, \\ Thailand \\ ${ }^{2}$ Department of Agricultural Technology, Faculty of Science and Technology, Thammasat University, Pathum \\ Thani, Thailand
}

*Corresponding author: sakunkans@gmail.com

\begin{abstract}
The use of corn wastes should increase production efficiency. The objective of this study was to evaluate anthocyanin content, phenolic content and antioxidant activity in kernel, cob, silk, and husk of purple waxy corn. Three varieties of purple waxy corn and a commercial check were planted in a randomized complete block design with three replications. Data were recorded for anthocyanin content, anthocyanin yield, phenolic content and antioxidant activity determined by 2,2-diphenyl-1-picrylhydrazyl radical scavenging ability (DPPH) and Trolox equivalent antioxidant capacity (TEAC) methods at edible stage (20 days after pollination; DAP) and seed stage (35 DAP). Significant differences between kernel maturity stages and among corn varieties and ear components were observed. Seed stage had significantly higher anthocyanin content, phenolic content and antioxidant activity than edible stage. KKU-OP and commercial check had the highest anthocyanin content, anthocyanin yield, DPPH and TEAC at edible and seed maturity stages. Corn silk had high anthocyanin content, DPPH and TEAC at seed stage, but corn cob had the highest anthocyanin content per unit of area. KKU-OP had the highest anthocyanin content, DPPH and TEAC at both maturity stages, whereas KKU-OP and KKU-WX111031 had the highest anthocyanin yield at edible and seed stages, respectively. Corn silk and corn cob had anthocyanins and can be used as a source of anthocyanins in food industry. KKU-OP and KKU-WX111031 had high anthocyanins and antioxidant activity and could be used as an alternative source of bioactive compounds for the functional food industry and a germplasm source for high anthocyanins.
\end{abstract}

Keywords: purple pigment, phenolics, free radical, antioxidants, Zea mays L. var. ceratina.

Abbreviations: ABTS_2,2'-azino-bis(3-ethylbenzothiazoline-6-sulphonic acid); CGE_cyandin-3-glucoside equivalent; DAP_days after pollination; DPPH_2,2-diphenyl-1-picrylhydrazyl radical scavenging ability; GAE_gallic acid equivalent; TAC_total anthocyanin content; TAY_total anthocyanin yield; TEAC_Trolox equivalent antioxidant capacity; TPC_total phenolic compound.

\section{Introduction}

Health problem caused by non-communicable diseases (NCD) including cardiovascular disease, diabetes, cancer, and chronic respiratory diseases is an important problem of modern life. A report revealed that 36 million people died from non-communicable diseases in 2008. The report estimated that, by 2020, NCDs are projected to cause almost three quarters as many deaths as communicable, maternal, prenatal and nutritional diseases and, by 2030, the deaths caused by the NCDs is expected to exceed the deaths caused by these disease (Sacco et al., 2013). The increase in NCDs is more rapid in low- and middle-income countries, and the diseases cause social, economic and health problems of people in these countries (Alwan et al., 2010). High dietary intake of fruits, vegetables and whole-grains is strongly associated with reduced risk of NCDs (Isabelle et al., 2010). These health benefits are attributed to the antioxidant compounds present in edible plants. Among them, anthocyanins are naturally occurring polyphenol pigments in many fruits, vegetables and cereals (He and Giusti, 2010). Positive association of the intake of fruits, vegetables and cereals with healthy biological effects including anticancer, anti-inflammatory and antioxidant characteristics in vivo has been reported (Norberto et al., 2013). World Health Organization and Food and Agriculture Organization launched a campaign to promote daily consumption a minimum of $400 \mathrm{~g}$ of fruits and vegetables per day (excluding starchy tubers) for the prevention of chronic diseases in 2003. The Ministry of Health in New Zealand recommends adults to eat at least three servings of vegetables and two of fruit each day (World Health Organization, 2003). The information obtained in the literature indicated that fruits, vegetables and cereals are important for health. Colored fruits, vegetables and cereals, in general, had higher quality than colorless food (Kim et al., 2000). These agricultural products have antioxidant activity against aging and various diseases. Colored waxy corn hybrids with high antioxidant activity were developed ( $\mathrm{Ji}$ et al., 2010). However, the information on antioxidant activity in waxy corn is still not sufficient. Corn (Zea mays L.) is a cereal and a source of carbohydrate that can serve the need for food, feed and fuel. Corn and its products are also rich in many phytochemicals such as carotenoids, phenolic compounds, anthocyanins, and tocopherols. Anthocyanin pigments in corn are responsible for its high antioxidant activity and have been shown to 
potentially reduce the risk of colon cancer (Hagiwara et al., 2001), prevent heart ischemia-reperfusion injury and hyperlipidemia (Toufektsian et al., 2008), anti-inflammatory effects (He and Giusti, 2010) and prevent diabetes and obesity (Tsuda et al., 2003). Europe and the United States are being more interested in purple corn, which is not a traditional source of dietary anthocyanins in these regions. For example, the ATHENA Collaborative Project (http://www.athena-flora.eu/) funded by the European commission provided a robust scientific foundation for improved dietary recommendations and concentrates on anthocyanins and related polyphenols of purple corn to promote health and to protect against chronic diseases.

The waxy corn (Zea mays L. var. ceratina) is consumed as fresh food and whole grain food mostly in Asian countries including China, Korea, Taiwan, Vietnam, Laos, Myanmar and Thailand, and the production area is increasing (Harakotr et al., 2014). Waxy corn products in forms of processed corn kernels, frozen corn kernels, and frozen corn ears are currently welcome in supermarket in the Europe and America (Ketthaisong et al., 2014; Lertrat and Thongnarin, 2008). The color range of waxy corn from white to black colors is correlated to phytochemical constituents and concentrations. Pigmented corn kernels had higher phytochemicals than did non-pigmented corn kernels (Harakotr et al., 2014; LopezMartinez et al., 2009). The interest in pigmented corn has increased in recent year and, therefore, the improvement of waxy corn hybrids with dark kernel colors and high phytochemicals is an objective of waxy corn breeders.

The information on phytochemicals and antioxidant activity in waxy is available mostly for corn kernels, and the information for different parts of ears is still lacking. The objective of this study was to evaluate anthocyanin content, phenolic content and antioxidant activity of four purple waxy corn genotypes in four ear components (kernel, cob, silk, and husk) at edible stage (20 DAP) and seed stage (35 DAP). The results reported in this study will be valuable for food nutritional researchers to develop co-products from corn production for use as natural antioxidants, dietary supplements and cosmetics.

\section{Results}

\section{Total anthocyanin content (TAC)}

Corn was harvested at edible stage and seed stage. Edible stage is defined as the stage of growth at 20 DAP, and seed stage (35 DAP) is defined as the growth stage between harvest maturity and physiological maturity, respectively. The kernel at seed stage is suitable for seed production, and the corn was harvest at seed moisture of about $40 \%$. At edible stage, KKU-OP (Fig. 1) had the highest TAC (151.3 mg CGE/100g of FW) followed by KKU-F1 Hybrid (93.0 mg CGE/100g of FW) and commercial check (76.3 mg CGE/100g of FW), respectively, whereas KKU-WX111031 had the lowest TAC (38.2 mg CGE/100g of FW) (Table 1). At seed stage, the values of TAC were higher than at edible stage in all corn genotypes. The values of TAC were 295.9 $\mathrm{mg}$ CGE/100g of FW in commercial check, $290.6 \mathrm{mg}$ CGE/100g of FW in KKU-F1 Hybrid, $225.6 \mathrm{mg}$ CGE/100g of FW in KKU-WX111031 and $202.3 \mathrm{mg}$ CGE/100g of FW KKU-OP (Table 2).

Significant differences $(\mathrm{P} \leq 0.05)$ among ear components were observed for TAC. Corn silk had the highest TAC (256.5 mg CGE/100g of FW) at edible stage followed by corn cob (49.0 mg CGE/100g of FW) and kernel (29.9 mg CGE/100g of FW), respectively, whereas husk had the lowest
TAC (23.5 mg CGE/100g of FW) (Table 1). At seed stage, corn silk was also highest for TAC (463.7 mg CGE/100g of $\mathrm{FW})$ followed by corn cob (271.3 mg CGE/100g of FW) and husk (210.3 mg CGE/100g of FW), respectively, whereas corn kernel had the lowest TAC (69.2 mg CGE/100g of FW) (Table 2).

The corn genotypes were significantly different $(\mathrm{P} \leq 0.05)$ for TAC in corn silk. At edible stage, KKU-OP had the highest TAC (408.5 mg CGE/100g of FW) followed by KKU-F1 Hybrid (289.1 mg CGE/100g of FW) and commercial check (249.5 mg CGE/100g of FW), respectively (Table 1). Corn genotypes were also significantly different $(\mathrm{P} \leq 0.05)$ for TAC in husk, and the values of TAC were much lower than those in corn silk, ranging from 4.7 to $48.7 \mathrm{mg}$ $\mathrm{CGE} / 100 \mathrm{~g}$ of $\mathrm{FW}$. Corn silk contributed to the largest portions of TAC in ears of all varieties (51.6-81.7\%), followed by cob (4.8-22.4\%), kernel (4.4-22.3\%), and husk $(1.5-13.1 \%)$ (Fig. 2). The results indicated that silk of purple waxy corn is a rich source of anthocyanins. At seed stage, the values of TAC followed a similar trend to those described for the edible stage (Table 2). Commercial check had the highest TAC in silk (500.8 mg CGE/100g of FW) followed by KKU-F1 hybrid (494.4 mg CGE/100g of FW) in husk and KKU-WX111031 (473.3 mg CGE/100g of FW) in silk, respectively, Whereas KKU-WX111031 had the lowest TAC in husk. KKU-F1 hybrid and KKU-OP had high TAC values of 456.1 and $419.3 \mathrm{mg} \mathrm{CGE} / 100 \mathrm{~g}$ of $\mathrm{FW}$, respectively, although the values were slightly lower than these of the above genotypes with high TAC values. Corn silk was an important source of TAC in all varieties, accounting for 39.2 to $53.7 \%$. In general, TAC values in husk were much lower than TAC values in silk except for KKU-F1 hybrid (494.4 mg CGE/100g of FW) (Fig. 2). With exception of KKU-F1 hybrid, corn husk corn husk contributed to the smallest portions of anthocyanin content in most corn genotypes. Although the values of TAC were high, the proportions of TAC in corn silk reduced at seed stage.

\section{Total anthocyanin yield (TAY)}

Total anthocyanin yield was calculated on hectare basis from total anthocyanin content in all ear components. At edible stage, KKU-OP had the highest TAY $(1,400.2 \mathrm{~g} \mathrm{CGE} \mathrm{ha-1)}$ followed by KKU-WX111031 (730.5 $\mathrm{g} \mathrm{CGE} \mathrm{ha}^{-1}$ ), KKU-F1 hybrid (703.5 $\mathrm{g} \mathrm{CGE} \mathrm{ha}^{-1}$ ) and commercial check (641.8 g CGE ha ${ }^{-1}$ ), respectively (Table 1). At seed stage, the highest values of TAY were obtained from commercial check $\left(4,130.1 \mathrm{~g} \mathrm{CGE} \mathrm{ha}^{-1}\right)$ followed by KKU-WX111031 and KKU-OP (3,009.2 and 2,858.3 $\mathrm{g} \mathrm{CGE} \mathrm{ha}^{-1}$, respectively), whereas the lowest value was obtained from KKU-F1 hybrid $\left(1,987.0 \mathrm{~g} \mathrm{CGE} \mathrm{ha}^{-1}\right)$ (Table 2). Significant differences $(\mathrm{P} \leq 0.05)$ were observed among corn genotypes and ear components for TAY. At edible stage, corn cob had the highest TAY $\left(1,396.7 \mathrm{~g} \mathrm{CGE} \mathrm{ha}^{-1}\right)$ followed by corn kernel $\left(1,082.8 \mathrm{~g} \mathrm{CGE} \mathrm{ha} \mathrm{ga}^{-1}\right)$ and husk (625.8 $\left.\mathrm{g} \mathrm{CGE} \mathrm{ha}^{-1}\right)$, respectively, whereas silk had the lowest TAY (370.7 g CGE $\mathrm{ha}^{-1}$ ) (Table 1). At seed stage, corn cob had the highest TAY $\left(5,575.7 \mathrm{~g} \mathrm{CGE} \mathrm{ha}^{-1}\right)$ followed by corn kernel $(4,283.6 \mathrm{~g}$ CGE $\left.\mathrm{ha}^{-1}\right)$ and husk $\left(1,805.5 \mathrm{~g} \mathrm{CGE} \mathrm{ha}{ }^{-1}\right)$, respectively, whereas corn silk had the lowest TAY (319.9 $\mathrm{g} \mathrm{CGE} \mathrm{ha}^{-1}$ ) (Table 2). At edible stage, cob of KKU-OP had the highest TAY $\left(2,806.6 \mathrm{~g} \mathrm{CGE} \mathrm{ha}^{-1}\right)$ followed by kernel of this variety $\left(1,558.5 \mathrm{~g} \mathrm{CGE} \mathrm{ha}^{-1}\right)$ and cob of KKU-WX111031 (1,338.3 $\mathrm{g}$ CGE $\left.\mathrm{ha}^{-1}\right)$, respectively, whereas the husk of commercial check had the lowest TAY (174.3 $\mathrm{g} \mathrm{CGE} \mathrm{ha}^{-1}$ ) (Table 1). Corn cob was the main source of TAY in KKU-WX111031, KKU-OP and commercial check, accounting for 39.2 to 
Table 1 Means for total anthocyanin content, total anthocyanin yield, total phenolic content, and antioxidant capacity determined by DPPH and TEAC methods at edible stage (20 DAP) of four varieties in four ear components of purple color waxy corn.

\begin{tabular}{|c|c|c|c|c|c|c|c|c|c|c|c|}
\hline \multirow{2}{*}{ Variety } & \multirow{2}{*}{$\begin{array}{l}\text { Ear } \\
\text { Part }\end{array}$} & \multirow{2}{*}{\multicolumn{2}{|c|}{ TAC }} & \multirow{2}{*}{\multicolumn{2}{|c|}{ TAY }} & \multirow{2}{*}{\multicolumn{2}{|c|}{ TPC }} & \multicolumn{4}{|c|}{ Antioxidant capacity } \\
\hline & & & & & & & & \multicolumn{2}{|c|}{ DPPH } & \multicolumn{2}{|l|}{ TEAC } \\
\hline KKU-WX111031 & & 38.19 & $\mathrm{c}^{1}$ & 730.50 & $\mathrm{~b}$ & 33.59 & $\mathrm{~b}$ & 20.62 & $\mathrm{~b}$ & 29.57 & $\mathrm{~b}$ \\
\hline KKU OP & & 151.32 & $\mathrm{a}$ & $1,400.20$ & $\mathrm{a}$ & 46.87 & $\mathrm{a}$ & 29.73 & $\mathrm{a}$ & 47.94 & $\mathrm{a}$ \\
\hline KKU $F_{1}$ hybrid & & 93.03 & $\mathrm{~b}$ & 703.50 & $\mathrm{~b}$ & 22.54 & $\mathrm{~d}$ & 16.07 & $\mathrm{~d}$ & 21.44 & $\mathrm{c}$ \\
\hline \multirow[t]{5}{*}{ Commercial check } & & 76.31 & $\mathrm{~b}$ & 641.80 & $\mathrm{~b}$ & 30.32 & $\mathrm{c}$ & 19.03 & $\mathrm{c}$ & 28.10 & $\mathrm{~b}$ \\
\hline & Kernel & 29.93 & $\mathrm{bc}$ & $1,082.80$ & $\mathrm{~b}$ & 21.38 & $\mathrm{c}$ & 13.15 & $\mathrm{c}$ & 22.95 & $\mathrm{c}$ \\
\hline & Cob & 48.95 & $\mathrm{~b}$ & $1,396.70$ & $\mathrm{a}$ & 30.90 & $\mathrm{~b}$ & 21.01 & $\mathrm{~b}$ & 31.10 & b \\
\hline & Silk & 256.50 & $\mathrm{a}$ & 370.70 & $\mathrm{~d}$ & 69.01 & $\mathrm{a}$ & 41.03 & $\mathrm{a}$ & 61.15 & $\mathrm{a}$ \\
\hline & Husk & 23.48 & $\mathrm{c}$ & 625.80 & $\mathrm{c}$ & 12.03 & $\mathrm{~d}$ & 10.25 & $\mathrm{~d}$ & 11.85 & d \\
\hline \multirow[t]{4}{*}{ KKU-WX111031 } & Kernel & 34.07 & de & $1,158.20$ & $\mathrm{~cd}$ & 23.97 & ef & 13.46 & ef & 22.28 & def \\
\hline & Cob & 34.15 & de & $1,338.30$ & $\mathrm{bc}$ & 28.36 & $\mathrm{e}$ & 20.24 & $\mathrm{~d}$ & 29.12 & de \\
\hline & Silk & 78.90 & $\mathrm{~cd}$ & 197.30 & $\mathrm{i}$ & 72.27 & $\mathrm{~b}$ & 39.64 & $\mathrm{~b}$ & 57.89 & b \\
\hline & Husk & 5.64 & $\mathrm{e}$ & 228.30 & hi & 9.78 & $\mathrm{~h}$ & 9.12 & $\mathrm{~g}$ & 8.98 & h \\
\hline \multirow[t]{4}{*}{ KKU OP } & Kernel & 45.84 & de & $1,558.50$ & $\mathrm{~b}$ & 23.79 & ef & 16.12 & $\mathrm{e}$ & 32.19 & $\mathrm{~d}$ \\
\hline & Cob & 115.97 & c & $2,806.60$ & $\mathrm{a}$ & 64.02 & $\mathrm{c}$ & 39.11 & $\mathrm{~b}$ & 65.78 & b \\
\hline & Silk & 408.54 & a & 449.40 & gh & 85.49 & $\mathrm{a}$ & 52.35 & $\mathrm{a}$ & 82.19 & $\mathrm{a}$ \\
\hline & Husk & 34.94 & de & 786.20 & ef & 14.19 & gh & 11.34 & fg & 11.59 & gh \\
\hline \multirow{4}{*}{ KKU $F_{1}$ hybrid } & Kernel & 16.53 & $\mathrm{e}$ & 674.50 & fg & 17.67 & $\mathrm{fg}$ & 10.48 & fg & 17.09 & fgh \\
\hline & Cob & 17.87 & $\mathrm{e}$ & 443.70 & $\mathrm{gh}$ & 15.81 & $\mathrm{gh}$ & 11.72 & fg & 12.92 & fgh \\
\hline & Silk & 289.06 & $\mathrm{~b}$ & 381.60 & hi & 42.53 & $\mathrm{~d}$ & 30.41 & $\mathrm{c}$ & 43.39 & c \\
\hline & Husk & 48.68 & de & $1,314.30$ & $\mathrm{c}$ & 14.14 & $\mathrm{gh}$ & 11.66 & fg & 12.38 & fgh \\
\hline \multirow[t]{4}{*}{ Commercial check } & Kernel & 23.29 & $\mathrm{e}$ & 939.90 & de & 20.08 & $\mathrm{fg}$ & 12.52 & $\mathrm{f}$ & 20.25 & efg \\
\hline & Cob & 27.80 & $\mathrm{e}$ & 998.40 & de & 15.43 & gh & 12.99 & $\mathrm{f}$ & 16.57 & fgh \\
\hline & Silk & 249.48 & $\mathrm{~b}$ & 454.50 & gh & 75.75 & $\mathrm{~b}$ & 41.72 & $\mathrm{~b}$ & 61.13 & $\mathrm{~b}$ \\
\hline & Husk & 4.68 & $\mathrm{e}$ & 174.30 & $\mathrm{i}$ & 10.01 & $\mathrm{~h}$ & 8.89 & $\mathrm{~g}$ & 14.43 & fgh \\
\hline
\end{tabular}

${ }^{1}$ Means in the same columns with different letters are significant $(\mathrm{P} \leq 0.05)$ determined by DMRT. TAC, total anthocyanin content (mg CGE/100g of FW); TAY; total anthocyanin yield $\left(\mathrm{g} \mathrm{CGE} \mathrm{ha}^{-1}\right)$; TPC, total phenolic compound (mg GAE/100g of FW); DPPH, 2,2-diphenyl-1-picrylhydrazyl radical scavenging ability (\% inhibition); TEAC, Trolox equivalent antioxidant capacity (\% of inhibition).

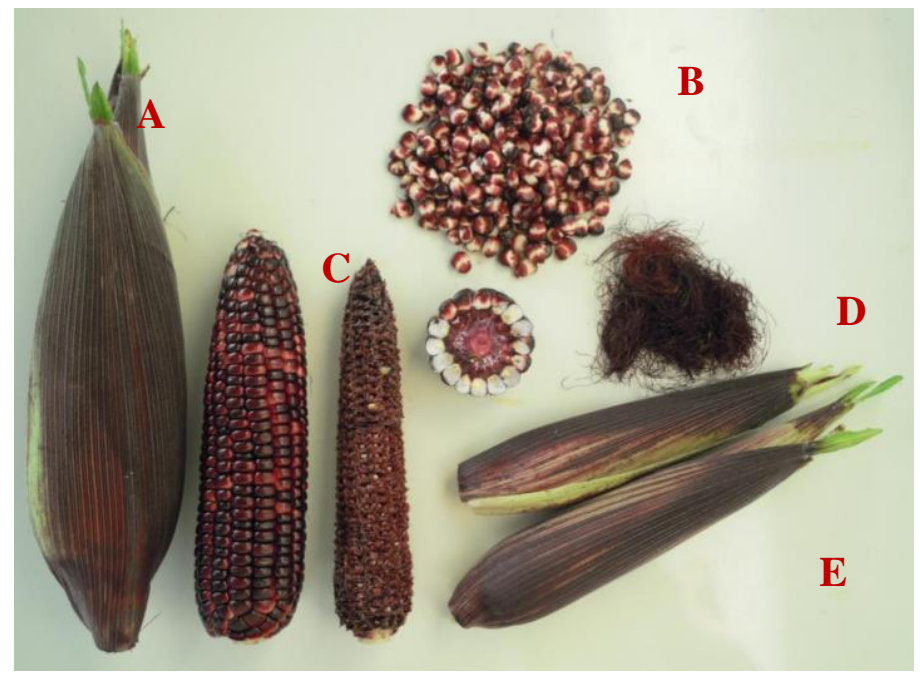

Fig 1. Ear (A) and ear components [kernel (B); cob (C); silk (D); husk (E)] of purple waxy corn KKU-OP variety at edible maturity stage (20 days after pollination).

$53.7 \%$ (Fig. 2). Corn husk was also the main source of TAY in KKU-F1 accounting for $46.7 \%$, whereas corn silk of all varieties contributed to the smallest portions for TAY, ranging from 6.8 to $17.7 \%$. At seed stage, cob of KKUWX111031 and kernel of commercial check had the highest TAY values of 9,602.9 and 9,439.0 $\mathrm{g} \mathrm{CGE} \mathrm{ha}^{-1}$, respectively, followed by cob of commercial check variety $(6,168.8 \mathrm{~g} \mathrm{CGE}$ ha $^{-1}$ ), whereas husk of KKU-WX111031 and silk of commercial check had the lowest TAY values (Table 2). Corn cob was the main source of TAY in KKU-WX111031 and KKU-F1 hybrid, and corn kernel was the main source of TAY in KKU-OP and commercial check. Corn husk contributed to the smallest portion of TAY in KKU-
WX111031, whereas corn silk contributed to the smallest portions of TAY in KKU-OP, KKU-F1 hybrid and commercial check (Fig. 2).

\section{Total phenolic compound (TPC)}

Significant differences $(\mathrm{P} \leq 0.05)$ among corn genotypes were founded for TPC at edible stage. KKU-OP had the highest TPC (46.87 mg GAE/100g of FW) followed by KKUWX111031 (33.59 mg GAE/100g of FW) and commercial check (30.32 mg GAE/100g of FW), respectively, whereas KKU-F1 hybrid had the lowest TPC (22.54 mg GAE/100g of FW) (Table 1). KKU-F1 hybrid had the highest TPC (46.87 
Table 2. Means for total anthocyanin content, total anthocyanin yield, total phenolic content, and antioxidant capacity determined by DPPH and TEAC methods at seed stage (35 DAP) in of four varieties in four ear components of purple color waxy corn at seed stage

\begin{tabular}{|c|c|c|c|c|c|c|c|}
\hline \multirow{2}{*}{ Variety } & \multirow{2}{*}{$\begin{array}{l}\text { Ear } \\
\text { Part }\end{array}$} & \multirow{2}{*}{\multicolumn{2}{|c|}{$\mathrm{TAC}$}} & \multirow{2}{*}{ TAY } & \multirow{2}{*}{ TPC } & \multicolumn{2}{|c|}{ Antioxidant capacity } \\
\hline & & & & & & DPPH & TEAC \\
\hline KKU-WX111031 & & 225.56 & $\mathrm{~b}$ & $3,009.20 \mathrm{~b}$ & $43.03 \mathrm{a}$ & $25.09 \mathrm{a}$ & $42.85 \mathrm{a}$ \\
\hline KKU-OP & & 202.26 & $\mathrm{~b}$ & $2,858.30 \mathrm{~b}$ & $44.96 \mathrm{a}$ & $27.85 \mathrm{a}$ & $45.85 \mathrm{a}$ \\
\hline KKU-F1 hybrid & & 290.62 & $\mathrm{a}$ & $1,987.00 \mathrm{c}$ & $46.50 \mathrm{a}$ & $27.47 \mathrm{a}$ & $44.73 \mathrm{a}$ \\
\hline \multirow[t]{5}{*}{ Commercial check } & & 295.94 & $\mathrm{a}$ & $4,130.10 \mathrm{a}$ & $44.65 \mathrm{a}$ & $26.56 \mathrm{a}$ & $46.04 \mathrm{a}$ \\
\hline & Kernel & 69.17 & $\mathrm{c}$ & $4,283.60 \mathrm{~b}$ & $24.97 \mathrm{~b}$ & $16.38 \mathrm{c}$ & $28.14 \mathrm{c}$ \\
\hline & $\mathrm{Cob}$ & 271.33 & $\mathrm{~b}$ & $5,575.70 \mathrm{a}$ & $59.82 \mathrm{a}$ & $31.83 \mathrm{~b}$ & $55.50 \mathrm{~b}$ \\
\hline & Silk & 463.65 & $\mathrm{a}$ & $319.90 \mathrm{~d}$ & $64.90 \mathrm{a}$ & $40.38 \mathrm{a}$ & $65.70 \mathrm{a}$ \\
\hline & Husk & 210.25 & $\mathrm{~b}$ & $1,805.50 \mathrm{c}$ & $29.45 \mathrm{~b}$ & $18.40 \mathrm{c}$ & $30.13 \mathrm{c}$ \\
\hline \multirow[t]{4}{*}{ KKU-WX111031 } & Kernel & 36.57 & $\mathrm{fg}$ & $1,950.40 \mathrm{ef}$ & 23.58 ghi & 14.3 ef & $23.67 \mathrm{de}$ \\
\hline & Cob & 384.12 & $a b$ & $9,602.90 \mathrm{a}$ & $66.13 \mathrm{ab}$ & $36.45 \mathrm{ab}$ & $69.41 \mathrm{a}$ \\
\hline & Silk & 478.30 & $\mathrm{a}$ & $349.00 \mathrm{gh}$ & $70.63 \mathrm{ab}$ & $40.95 \mathrm{a}$ & $64.67 \mathrm{a}$ \\
\hline & Husk & 3.26 & g & $134.40 \mathrm{~h}$ & $11.79 \mathrm{i}$ & $8.65 \mathrm{f}$ & $13.64 \mathrm{e}$ \\
\hline \multirow[t]{4}{*}{ KKU-OP } & Kernel & 81.03 & efg & $4,254.10 \mathrm{c}$ & 29.79 efgh & $19.57 \mathrm{de}$ & $36.38 \mathrm{bcd}$ \\
\hline & $\mathrm{Cob}$ & 178.59 & $\mathrm{de}$ & $3,274.20 \mathrm{~cd}$ & $54.01 \mathrm{bcd}$ & $29.81 \mathrm{bc}$ & $45.81 \mathrm{~b}$ \\
\hline & Silk & 419.31 & $a b$ & $419.30 \mathrm{gh}$ & $58.63 \mathrm{abc}$ & $39.59 \mathrm{a}$ & $64.39 \mathrm{a}$ \\
\hline & Husk & 130.13 & def & $3,485.50 \mathrm{~cd}$ & $37.39 \mathrm{defg}$ & 22.44 cde & $36.82 \mathrm{bcd}$ \\
\hline \multirow[t]{4}{*}{ KKU-F1 hybrid } & Kernel & 25.80 & $\mathrm{fg}$ & $1,490.70 \mathrm{fg}$ & 26.45 fghi & $16.25 \mathrm{def}$ & $25.77 \mathrm{de}$ \\
\hline & $\mathrm{Cob}$ & 186.11 & de & $3,256.90 \mathrm{~cd}$ & 44.29 cde & $24.27 \mathrm{~cd}$ & $38.76 \mathrm{bcd}$ \\
\hline & Silk & 456.13 & $a b$ & 380.10 gh & $72.32 \mathrm{a}$ & $45.35 \mathrm{a}$ & $72.07 \mathrm{a}$ \\
\hline & Husk & 494.45 & $\mathrm{a}$ & $2,820.40 \mathrm{de}$ & 42.94 cdef & $24.01 \mathrm{cde}$ & $42.32 \mathrm{bc}$ \\
\hline \multirow[t]{4}{*}{ Commercial check } & Kernel & 133.26 & def & $9,439.00 \mathrm{a}$ & $20.06 \mathrm{hi}$ & $15.38 \mathrm{def}$ & 26.72 cde \\
\hline & Cob & 336.48 & $\mathrm{bc}$ & $6,168.80 \mathrm{~b}$ & $74.85 \mathrm{a}$ & $36.79 \mathrm{ab}$ & $68.02 \mathrm{a}$ \\
\hline & Silk & 500.84 & $\mathrm{a}$ & $131.10 \mathrm{~h}$ & $58.02 \mathrm{abc}$ & $35.6 \mathrm{ab}$ & $61.69 \mathrm{a}$ \\
\hline & Husk & 213.16 & $\mathrm{~cd}$ & 781.6 fgh & $25.67 \mathrm{ghi}$ & $18.48 \mathrm{de}$ & 27.75 cde \\
\hline
\end{tabular}

${ }^{1}$ Means in the same columns with different letters are significant $(\mathrm{P} \leq 0.05)$ determined by DMRT. TAC, total anthocyanin content (mg CGE/100g of FW); TAY; total anthocyanin yield (g CGE ha ${ }^{-1}$ ); TPC, total phenolic compound (mg GAE/100g of FW); DPPH, 2,2-diphenyl-1-picrylhydrazyl radical scavenging ability (\% inhibition); TEAC, Trolox equivalent antioxidant capacity (\% of inhibition).

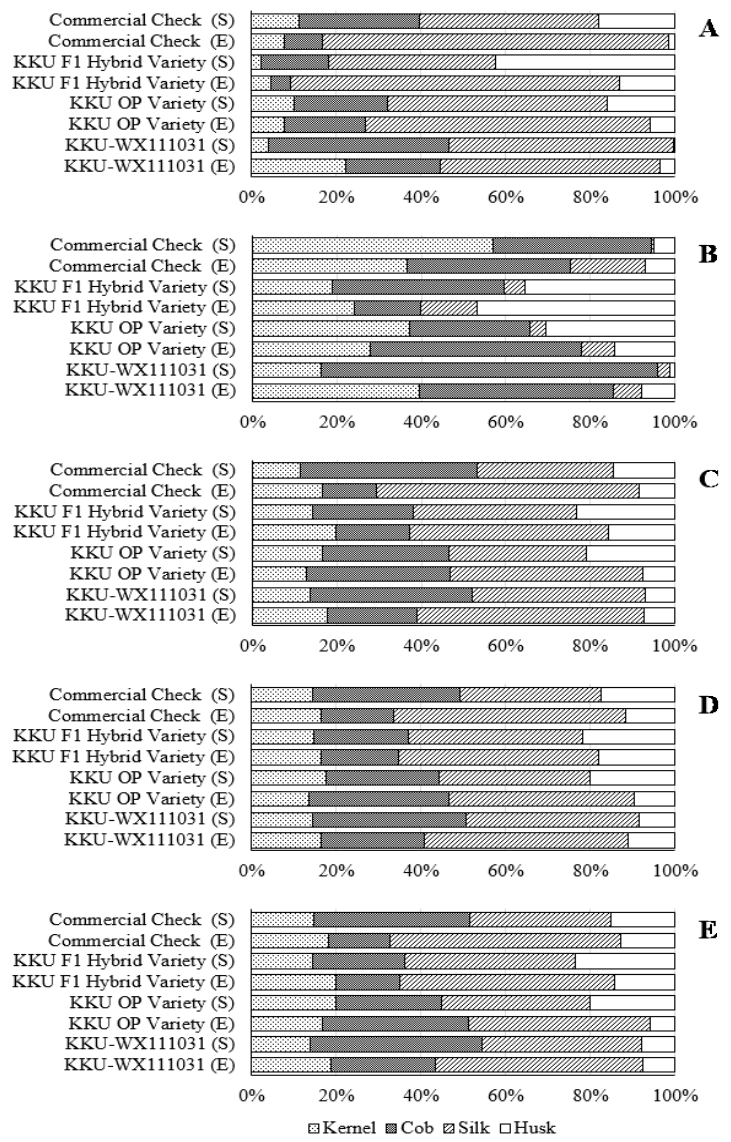

Fig 2. Relationship between total anthocyanin content (A), total anthocyanin yield (B), total phenolic compound (C), and antioxidant capacities,2,2-diphenyl-1-picrylhydrazyl radical scavenging ability, (D); Trolox equivalent antioxidant capacity, (E) in 4 varieties of purple color waxy corn at edible maturity stage and at seed stage. 
mg GAE/100g of FW) at seed stage although the differences among varieties were not significant (Table 2). Significant differences $(\mathrm{P} \leq 0.05)$ among ear components were founded for TPC at edible stage and seed stage. At edible stage, corn silk had the highest TPC ( $69.01 \mathrm{mg}$ GAE/100g of FW) followed by corn cob (30.90 mg GAE/100g of FW) and kernel (21.38 mg GAE/100g of FW), respectively, whereas husk had the lowest TPC (12.03 mg GAE/100g of FW) (Table 1). At seed stage, corn silk and cob had the highest TPC (64.90 and $59.82 \mathrm{mg} \mathrm{GAE} / 100 \mathrm{~g}$ of FW, respectively), whereas corn husk and kernel had the lowest TPC (29.45 and $24.97 \mathrm{mg} \mathrm{GAE} / 100 \mathrm{~g}$ of $\mathrm{FW}$, respectively) (Table 2). At edible stage, KKU-OP had the highest TPC in silk $(85.49 \mathrm{mg}$ $\mathrm{GAE} / 100 \mathrm{~g}$ of $\mathrm{FW})$ followed commercial check $(75.75 \mathrm{mg}$ GAE/100g of FW) and KKU-WX111031 (72.27 mg GAE/100g of FW), respectively, whereas commercial check and KKU-WX111031 had the lowest TPC in husk (10.01 and $9.78 \mathrm{mg} \mathrm{GAE} / 100 \mathrm{~g}$ of FW, respectively) (Table 1). Corn silk was the main source of TPC in all varieties, accounting for 45.6 to $62.5 \%$, whereas corn husk contributed to the smallest proportions of this compounds in all varieties (Fig. 2). At seed stage, the corn cob of commercial check and silk of KKU-F1 hybrid had the highest TPC (74.85 and $72.32 \mathrm{mg}$ $\mathrm{GAE} / 100 \mathrm{~g}$ of $\mathrm{FW}$, respectively) followed by silk and cob of KKU-WX111031 (70.63 and 66.13 mg GAE/100g of FW, respectively) (Table 2). However, the lowest TPC (11.79 mg GAE/100g of FW) was founded in husk of KKU-WX111031. Corn silk was the main source of TPC in KKU-WX111031, KKU-OP and KKU-F1 hybrid, whereas corn cob was the main source of TPC in commercial check (Fig. 2).

\section{Antioxidant capacity}

Differences among waxy corn varieties at edible stage were significant $(\mathrm{P} \leq 0.05)$ for parameters related to antioxidant capacity (2,2-diphenyl-1-picrylhydrazyl radical scavenging ability, DPPH; Trolox equivalent antioxidant capacity, TEAC). The lowest values for DPPH and TEAC were obtained from KKU-F1 hybrid (16.07 and $21.44 \%$ of inhibition, respectively), whereas the highest values were obtained from KKU-OP (29.73 and 47.94\% of inhibition, respectively) (Table 1). The varieties with the highest DPPH values had the highest TEAC values. However, differences among waxy corn varieties at seed stage were not significant for parameters related to antioxidant capacity. KKU-OP and commercial check had relatively high values for DPPH and TEAC (Table 2). Significant differences $(\mathrm{P} \leq 0.05)$ among ear components were founded for parameters related to antioxidant capacity at edible stage and seed stage. At edible stage, the highest values of DPPH and TEAC were obtained from corn silk (41.03 and $61.15 \%$ of inhibition, respectively), whereas the lowest values were obtained from husk (10.25 and $11.85 \%$ of inhibition, respectively) (Table 1). DPPH values and TEAC values at seed stage followed a pattern similar to that at edible stage. The highest values of DPPH and TEAC were obtained from corn silk (40.38 and $65.70 \%$ of inhibition, respectively), whereas the lowest values were obtained from corn kernel (Table 2). At edible stage, silk of KKU-OP had the highest DPPH and TEAC (52.35 and $82.19 \%$ of inhibition, respectively) followed by silk of KKUWX111031 and commercial check, whereas husk of commercial check and KKU-WX111031 had the lowest DPPH and TEAC (Table 1). Corn silk was the main source of DPPH and TEAC in all varieties, whereas corn husk and kernel contributed the smallest proportions of DPPH and TEAC (Fig. 2).
At seed stage, corn silk of all genotypes had the highest DPPH and TEAC. Corn cob of KKU-WX1110331 and commercial check had the highest values of TEAC. The lowest values of DPPH and TEAC were obtained from husk of KKU-WX111031 (Table 2). Corn silk was the main source of DPPH and TEAC in most varieties exception for KKUWX1110331 and commercial check in which corn cob contributed to the greatest proportions of TEAC (Fig. 2).

\section{Discussion}

Antioxidants and their capacities in waxy corn at different maturation stage

Waxy corn has high variations in kernel color, starch properties and nutritionally important components (Harakotr et al., 2014; $\mathrm{Hu}$ and $\mathrm{Xu}, 2011$; Kethaisong et al., 2014). The kernel colors of waxy corn include white, yellow, purple, blue and black. Previous study indicated that kernel colors of waxy corn were closely related to phytochemical constituents and concentrations. In this study, waxy corn varieties with purple and black kernels were selected because they are rich in anthocyanins and phenolic compounds, and the results indicated that KKU-OP had the highest total anthocyanin content at edible stage (151.3 mg CGE/100g of fresh weight $(\mathrm{FW})$ ). In previous investigations with many crops, total anthocyanin contents were $138.1 \mathrm{mg}$ CGE/100g in black colored waxy corn (Hu and $\mathrm{Xu}, 2011),(2.2 \mathrm{mg} \mathrm{CGE} / 100 \mathrm{~g}$ in red rice and $15.3 \mathrm{mg} \mathrm{CGE} / 100 \mathrm{~g}$ in blue wheat (Abdel-Aal et al., 2006). Total anthocyanin contents (ranging from 4.68 to $500.84 \mathrm{mg} \mathrm{CGE} / 100 \mathrm{~g}$ of FW in all parts of ear) in waxy corn in this study were higher than those in previous study. The differences in the results among different studies were due largely to plant species and plant genotypes and plant parts. The results in this study and previous studies indicate that there is variation in anthocyanin content in waxy corn and breeding for high anthocyanins in waxy corn is possible.

At seed stage, commercial check and KKU-F1 Hybrid had the highest total anthocyanin content $(295.9$ and $290.6 \mathrm{mg}$ CGE/100g of FW, respectively), whereas KKU-OP had the lowest total anthocyanin content. Seed stage, on average, also had higher anthocyanin contents ranging from 25 to $83 \%$ than did edible stage, when all genotypes were considered. Genotype and maturity stage were the important sources of variation in anthocyanin content in waxy corn. In previous investigation in waxy corn, corn harvested at dry kernel stage had significant and slightly higher anthocyanin content than did corn harvested at fresh kernel stage (Khampas et al., 2013). Higher anthocyanin content at seed stage would be possibly due to longer time for anthocyanin accumulation. Kernel development in all corn genotypes was characterized by the change in pericarp colors varying from light color to dark color. Changes in color reflected changes in the profiles of pigments synthesized in corn such as anthocyanins during maturation ( $\mathrm{Hu}$ and $\mathrm{Xu}, 2011)$. KKU-OP had the highest anthocyanin yield $\left(1,402 \mathrm{~g} \mathrm{CGE} \mathrm{ha} \mathrm{ha}^{-1}\right)$ at edible stage followed by commercial check $\left(4,130 \mathrm{~g} \mathrm{CGE} \mathrm{ha}^{-1}\right)$ at the same growth stage. The results indicate that the purple waxy corn is abundant of anthocyanins, which are strong free radical scavengers calculated by weight and/or capita. These corn varieties can be used as alternative materials for functional food products and nutraceutical industry. Waxy corn is consumed as a fresh vegetable at immature stage and as whole grain at mature stage. The corn-based antioxidants are more easily accepted among malnourished and lowincome consumers, particularly in the rural areas of developing countries (Chander et al., 2008). 
Utilization of waxy corn co-products in the functional food industry and beyond

Wastes from industry and agriculture can be used for production of natural food colorants and antioxidants. Corn tassels could be used as a source of phenols to prolong the shelf life of fats and oils (Mohsen and Ammar, 2009). In Andean purple corn, the co-products of corn processing were used as food additives or natural antioxidants (CevallosCasals and Cisnoros-Zevallos, 2003). To the best of our knowledge so far, this information is not available for waxy corn. Corn silk is currently reported as a rich source of various bioactive compounds such as protein, vitamins, carbohydrates, calcium, magnesium, volatile oil, alkaloids, flavonoids and phenolic compounds that possess high antioxidative effects (Ebrahimzadeh et al., 2008). Therefore, corn silk can be used as a food ingredients and flavoring. In this study, the highest values of antioxidants and their capacities were obtained from corn silk across all genotypes at both edible and seed stages. Although seed stage had slightly high concentration of antioxidant compounds than did edible stage, edible stage is the harvest growth stage for commercial production of vegetable waxy corn. At edible stage, averaged anthocyanin content was $256.5 \mathrm{mg}$ CGE/100g of FW. The reason underlying high anthocyanin content in corn silk compared to other parts of ear is still unresolved, and further investigations on phytochemical changes during seed maturation are still required. However, the information on anthocyanin content in different components of ears of purple waxy corn is useful for utilization of purple waxy corn as a source of anthocyanins.

In previous studies in other crop species, anthocyanin contents were $236 \mathrm{mg} \mathrm{CGE} / 100 \mathrm{~g}$ of FW in blackcurrant, 68 $\mathrm{mg} \mathrm{CGE} / 100 \mathrm{~g}$ in cowberry (Kahkonen et al., 2003) and 202 mg CGE/100g in strawberry (Patras et al., 2009). Corn silk of purple waxy corn has high anthocyanin content and is a good source of bioactive compounds (Sarepoua et al., 2015). The overall findings regarding the antioxidants found in colored corn silk were in accordance with those reported by other researchers. Therefore, corn silk of colored waxy corn is a valuable source of natural antioxidants for functional food products and cosmetic products, and the use of corn silk should reduce agricultural waste.

Corn cob had lower total anthocyanin content than did corn silk at edible and seed stages. However, but this it had higher pigments than did corn kernel and seed. In other studies, corn cob of Chinese purple corn had anthocyanin content of $92 \mathrm{mg}$ CGE/100g (Yang and Zhai, 2010), and corn cob of Andean purple corn had anthocyanin contents ranging from 290 to 34,000 mg CGE/100g (de Pascual-Teresa et al., 2002; Jing et al., 2007). Anthocyanins found in purple corn cob in this study was higher than that found in Chinese purple corn but it was low than those found in Andean purple corn. Different results among different studies indicate the variation in anthocyanin content in purple waxy corn, and improvement of corn cob for high anthocyanin content would be possible. Although colored waxy corn cob has a lower concentration of anthocyanin than Andean purple corn, waxy corn is utilized as fresh food at edible stage or as a raw materials for whole grain foods at mature stage (Harakotr et al., 2014). Waxy corn matures earlier than normal grain corn, exhibits better nutrient quality and presents improved palatability ( $\mathrm{Hu}$ and $\mathrm{Xu}, 2011)$.

In this study, the correlation coefficients between total phenolic content and DPPH and TEAC were positive and significant at both edible stage and seed stage, and the correlation coefficients between total anthocyanin content and DPPH and TEAC were also positive and significant (data not reported). These correlation coefficients ranged between 0.73 and $0.99 \quad(\mathrm{P} \leq 0.01)$, and the correlation coefficients between anthocyanin content and phenolic content were $0.77(\mathrm{P} \leq 0.01)$ at edible stage and $0.70(\mathrm{P} \leq 0.01)$ at seed stage (data not reported).

In previous investigation in purple waxy corn, total anthocyanin content was significantly correlated with TEAC, DPPH, and total phenolic content, and total phenolic content had positive and significant correlations with TEAC and DPPH (Khampas et al., 2013). The authors also found that correlation between DPPH and TEAC was also positive and significant. The results indicated that phenolics and anthocyanins contributed to antioxidant activity in purple waxy corn and any antioxidant assay in this study can be used for evaluation of antioxidant in waxy corn because of high association between the methods.

The interest in anthocyanin pigments from purple waxy corn has increased in recent year because of their possible utilization as functional food products. Purple corn cob is an anthocyanin-containing agricultural waste and it is a good source of anthocyanin for use in food, pharmaceutical and cosmetic industries. In this study, anthocyanin yields of 1,396 and 5,575 $\mathrm{g} \mathrm{C} \mathrm{G} \mathrm{ha}^{-1}$ at edible and seed stages, respectively were estimated. The results indicated that the cob of colored waxy corn possessed excellent antioxidant capacity, and it is a promising source of anthocyanins for use in food industry.

\section{Materials and Methods}

\section{Plant materials and crop management}

Three waxy corn varieties (KKU-WX111031, KKU-F1 Hybrid and KKU-OP) improved by the plant breeding research center for sustainable agriculture, Khon Kaen University, Thailand, and one commercial variety (commercial check) from seed company were used. These waxy corns were evaluated in a randomized complete block design with three replications at the Research Farm in Mahasarakam University in the dry season 2011 (November 2011 through January 2012). The plot size was single-row plot with $5 \mathrm{~m}$ long and spacing of $0.8 \mathrm{~m}$ between row and $0.25 \mathrm{~m}$ between plants within rows. The recommended practices for the commercial production of vegetable corn were followed. The populations were sib-pollinated with the plants in the same populations to avoid contamination of stray pollens. Ears were harvested by hand at the milk stage (20 DAP) and seed stage (35 DAP). Seed stage is described as the stage that suitable for seed production, and it is between physiological maturity stage and dry harvest maturity stage. The moisture content of the kernels is about $40 \%$. At milk stage, ears from physiologically undamaged 10 waxy corn ears were manually separated into different ear components including husk, silk, kernel and cob. The samples were frozen in liquid nitrogen to stop the enzymatic activity and stored at $-20^{\circ} \mathrm{C}$ until analysis.

\section{Sample Extraction}

Anthocyanins in distinct ear parts were extracted according to the method previously described by Yang et al. (2009) with slight modification. Portion of $0.5 \mathrm{~g}$ samples were put into a conical flask containing $25 \mathrm{~mL}$ of acidified methanol (methanol-1\% citric acid, 80:20 v/v) mixed well and stored for $24 \mathrm{~h}$ at $4{ }^{\circ} \mathrm{C}$. The solution was then transferred to a tube and centrifuged at $11,538 \times \mathrm{g}$ for $10 \mathrm{~min}$ at $4{ }^{\circ} \mathrm{C}$. Further, the 
supernatants were collected and kept at $-20{ }^{\circ} \mathrm{C}$ in the dark until analysis.

\section{Determination of total anthocyanin content (TAC) and total anthocyanin yield (TAY)}

Total anthocyanin content was measured using the $\mathrm{pH}$ differential method as described by Giusti and Wrolstad (2001). A UV-vis spectrophotometer (UV-1700 Pharmaspec, Shimadzu, Japan) was used to measure the absorbance at 510 and $700 \mathrm{~nm}$. Anthocyanin levels were expressed as $\mathrm{mg}$ of cyanidin-3-glucoside equivalents per $\mathrm{g}$ of fresh weight $(\mathrm{mg}$ CGE/100g of FW), using the reported molar extinction coefficient of $26900 \mathrm{M}^{-1} \mathrm{~cm}^{-1}$ and a molecular weight of $449.2 \mathrm{~g} / \mathrm{mol}$. Anthocyanin yield was also calculated on hectare basis from anthocyanin content in all parts of ears by weight.

\section{Determination of total phenolic content (TPC)}

Total phenolic contents were determined using FolinCiocalteu (F-C) method described by $\mathrm{Hu}$ and $\mathrm{Xu}$ (2011). Briefly, the appropriate dilutions of extracts were oxidized with F-C reagent, and the reaction was neutralized with sodium carbonate. The absorbance of the resulting blue color was measured at $765 \mathrm{~nm}$ after $90 \mathrm{~min}$, and the phenolic content was expressed as mg of gallic acid equivalents (GAE) per 100g of fresh weight (mg GAE/ 100g of FW).

\section{Determination of antioxidant activity}

The capacity for scavenging 2,2-diphenyl-1-picrylhydrazyl (DPPH) radicals was assessed by measuring the bleaching of a black-coloured methanol solution containing DPPH radicals as described by Yang and Zhai (2010). Briefly, $0.1 \mathrm{mM}$ solution of methanolic DPPH solution was prepared. The initial absorbance of the DPPH in methanolic was determined at $517 \mathrm{~nm}$ and did not change throughout the period of assay. An aliquot $(0.1 \mathrm{~mL})$ of each sample (with appropriate dilution if necessary) was added with $3 \mathrm{~mL}$ of methanolic DPPH solution. Discolorations were measured at $517 \mathrm{~nm}$ after incubation for $30 \mathrm{~min}$ at $30{ }^{\circ} \mathrm{C}$ in the dark. Measurements were performed at least in triplicate. The percentage of $\mathrm{DPPH}^{\circ}$ was calculated as:

$\% \mathrm{DPPH}$ reduction $=\left(\mathrm{Abs}_{\text {control }}-\mathrm{Abs}_{\text {sample }}\right) \times 100 / \mathrm{Abs}$ control Where Abs control is the absorbance of the control, and Abs sample is the absorbance of the sample.

Trolox equivalent antioxidant capacity (TEAC) assay, which measures the reduction of radical cations of ABTS by antioxidants was conducted as described by Yang and Zhai (2010). The radical cation $\mathrm{ABTS}^{\cdot+}$ was generated by persulfate oxidation of ABTS. A mixture $(1: 1, \mathrm{v} / \mathrm{v})$ of ABTS $(7.0 \mathrm{mM})$ and potassium persulfate $(4.95 \mathrm{mM})$ was allowed to stand overnight at room temperature in the dark to form radical cation $\mathrm{ABTS}^{*+}$. A working solution was diluted with phosphate buffer solution to reach absorbance values between 1.0 and 1.5 at $731 \mathrm{~nm}$ (constant initial absorbance values must be used for standard and samples). An aliquot $(0.1 \mathrm{ml})$ of each samples (with appropriate dilution if necessary) were mixed with the working solution $(3.9 \mathrm{ml})$, and the decrease of absorbance was measured at $731 \mathrm{~nm}$ after $10 \mathrm{~min}$ at $37{ }^{\circ} \mathrm{C}$ in the dark. Aqueous phosphate buffer solution $(3.9 \mathrm{ml}$, without $\mathrm{ABTS}^{*+}$ solution) was used as a control. The ABTS ${ }^{++}$ scavenging rate was calculated as:

$\%$ ABTS reduction $=\left(\mathrm{Abs}_{\text {initial }}-\mathrm{Abs}_{\text {final }}\right) \times 100 / \mathrm{Abs}_{\text {initial }}$ Where Abs initial is the absorbance of the control, and Abs final is the absorbance of the sample.

\section{Statistical analysis}

The data were presented as the means of three replicates \pm standard deviation. The results were subjected to variance analysis and Duncan's multiple range test (DMRT) $(\mathrm{P} \leq 0.05)$ was used to identify significant differences between group means using the JMP Pro software (version 10, SAS Institute Inc., Chicago, IL, USA).

\section{Conclusions}

Corn genotypes, ear components and maturity stages were significantly different for total anthocyanin content, total anthocyanin yield, total phenolic compound and parameters related to antioxidant capacity (2,2-diphenyl-1-picrylhydrazyl radical scavenging ability; DPPH and Trolox equivalent antioxidant capacity; TEAC). KKU-OP had the highest antioxidants and their capacities at edible stage, whereas commercial check had the highest antioxidants and their capacities at seed stage. Corn silk harvested at edible and seed maturity stages had the highest anthocyanin, phenolic content and the scavenging abilities against DPPH and ABTS radicals than other ear components. Corn cob also had high total anthocyanin yield in each genotype. KKU-OP had the highest total anthocyanin content and antioxidant activity in corn silk at both maturation stages, whereas KKU-OP and KKU-F $F_{1}$ hybrid had the highest anthocyanin yield in corn cob at edible and seed maturation stages, respectively. Purple waxy corn with high anthocyanin content and strong radical scavenging capacity can be used as a promising source of anthocyanins for functional food products, cosmetic and nutraceutical products. Corn silk and cob, regarded as waste from corn production, also have high bioactive compounds and can be used as raw materials for production of anthocyanins that can be used as natural food colorant by the food industry.

\section{Acknowledgements}

The research project was financially supported by Mahasarakam University and also supported by Faculty of Technology, Mahasarakam University. The authors acknowledge the Plant Breeding Research Center for Sustainable Agriculture, Faculty of Agriculture, Khon Kaen University for donation of waxy corn germplasm and preparing experimental facility. The Laboratory Equipment Center, Mahasarakham University is acknowledged for guidance of the antioxidant analyses.

\section{References}

Abdel-Aal ESM, Young JC, Rabalski I (2006) Anthocyanin composition in black, blue, pink, purple, and red cereal grains. J Agri Food Chem. 54:4696-4704.

Alwan A, MacLean DR, Riley LM, Espaignet ET, Mathaers CD, Stevens GA, Bettcher D (2010) Monitoring and surveillance of chronic non-communicable diseases: progress and capacity in high-burden countries. Lancet. 376:1861-1868.

Cevallos-Casals BA, Cisnoros-Zevallos L (2003) Stoichiometric and kinetic studies of phenolic antioxidants from Andean purple corn and red-flesh sweet potato. J Agri Food Chem. 51:3313-3319.

Chander S, Meng Y, Zhang Y, Yan J, Li J (2008) Comparison of nutritional traits variability in selected eighty-seven inbreds from Chinese maize (Zea mays L.) germplasm. J Agri Food Chem. 56:6506-6511. 
de Pascual-Teresa S and Sanchez-Ballesta MT (2008) Anthocyanins: from plant to health. Photochem Rev. 7:281-299.

Ebrahimzadeh MA, Pourmorad F, Hafezi S (2008) Antioxidant activities of Iranian corn silk. Turkish J Biol. 32:43-49.

Giusti MM, Wrolstad RE (2001) Characterization and measurement of anthocyanins by UV-visible spectroscopy. In: Wrolstad RE, Acree TE, An H, Decker EA, Penner MA, Reid DS, Schwartz SJ, Shoemaker CF, Sporns P (Eds) Current protocols in food analytical chemistry. John Wiley and Sons, New York

Hagiwara A, Miyashita K, Nakanishi T, Sano M, Tamano S, Kadota T, Koda T, Nakamura M, Imaida K, Ito N, Shira T (2001) Pronounced inhibition by a natural anthocyanin,

Harakotr B, Suriharn B, Tangwongchai R, Scott MP, Lertrat K (2014) Anthocyanins and antioxidant activity in coloured waxy corn at different maturation stages. J Funct Food. 9:109-118.

He J, Giusti MM (2010) Anthocyanins: Natural colorants with health-promoting properties. Annu Rev Food Sci Technol. 1:163-187.

Hu QP, Xu JG (2011) Profiles of carotenoids, anthocyanins, phenolics, and antioxidant activity of selected color waxy corn grains during maturation. J Agri Food Chem. 59:20262033.

Isabelle M, Lee BL, Lim, MT, Koh WP, Huang D, Ong CN (2010) Antioxidant activity and profiles of common fruits in Singapore. Food Chem. 123:77-84.

Ji CH, Lee HB, Yamakawa T (2010) Major agricultural characteristics and antioxidants analysis of the new developed colored waxy corn hybrids. J Fac Agr Kyushu. U55:55-59.

Jing P, Noriega V, Schartz SJ, Giusti MM (2007) Effects of growing conditions on purple corncob (Zea mays L.) anthocyanins. J Agri Food Chem. 55:8625-8629.

Khampas S, Lertrat K, Lomthaisong K, Suriharn B (2013) Variability in phytochemicals and antioxidant activity in corn at immaturity and physiological maturity stages. Int Food Res J. 20(6):3149-3157.

Kim SL, Hwang JJ, Song JC and Jung KH (2000) Extraction, purification and quantification of anthocyanins in colored rice, black soybean and black waxy corn. Korean J Breed. 32:146-152

Kahkonen MP, Heinamaki J, Ollilainen V, Heinonen M (2003) Berry anthocyanins: isolation, identification and antioxidant activities. J Sci Food Agr. 83:1403-1411.

Ketthaisong D, Suriharn B, Tangwongchai R, Lertrat K (2014) Changes in physicochemical properties of waxy corn starches at different stages of harvesting. Carbohyd Polym. 98:241-248.

Lertrat K, Thongnarin N (2008) Novel approach to eating quality improvement in local waxy corn: Improvement of sweet taste in local waxy corn variety with mixed kernels from super sweet corn. Acta Hort. 769:145-150.
Lopez-Martinez LX, Oliart-Ros RM, Valerio-Alfaro G, Lee CH, Parkin Kl and Garcia HS (2009) Antioxidant activity, phenolic compounds and anthocyanins content of eighteen strains of Mexican maize. LWT-Food Sci Tech. 42:11871192.

Mohsen SM, Ammar ASM (2009) Total phenolic contents and antioxidant activity of corn tassel extracts. Food Chem. 112:595-598.

Norberto S, Silva S, Meireles M, FariaA, Pintado M, Calhau C (2013) Blueberry anthocyanins in health promotion: A metabolic overview. J Funct Foods. 5:1518-1528.

Patras A, Brunton NP, Pieve SD, Butler F (2009) Impact of high pressure processing on total antioxidant activity, phenolic, ascorbic acid, anthocyanin content and colour of strawberry and blackberry purées. Innov Food Sci Emerg Technol. 10:303-313.

purple corn color, of 2-amino-1-methyl-6-phenylimidazo[4,5b]pyridine ( $\mathrm{PhIP}$ )-associated colorectal carcinogenesis in maleF344 rats pretreated with 1,2-dimethylhydrazine. Cancer Lett. 171:17-25.

Reid DS, Schwartz SJ, Shoemaker CF, Sporns P (Eds) Current protocols in food analytical chemistry (Vol. 1, pp. F1.2.1-F1.2.13). John Wiley \& Sons, New York

Sacco RL, Smith SC, Holmes D, Shurin S, Brawley O, Cazap E, Glass R, Komajda M, Koroshetz W, Mayer-Davis E, Mbanya JC, Sledge G, Varmus H (2013) Accelerating progress on non-communicable diseases. Lancet. 382:e4e5.

Sarepoua E, Tangwongchai R, Suriharn B, Lertrat K (2015) Influence of variety and harvest maturity on phytochemical content in corn silk. Food Chem. 169:424-429.

Toufektsian MC, de Lorgeril M, Nagy N, Salen P, Donati MB, Giordano L, Mock HP, Peterek S, Matros A, Petroni K, Pilu R, Rotillio D, Tonelli C, de Leiris J, Boucher F, Martin C (2008) Chronic dietary intake of plant-derived anthocyanins protects the rat heart against ischemiareperfusion injury. J Nutr. 138:747-752.

Tsuda T, Horio F, Uchida K, Aoki H, Osawa T (2003) Dietary cyanidin 3-O- $\beta$-D-glucoside-rich purple corn color prevents obesity and ameliorates hyperglycemia in mice. $\mathbf{J}$ Nutr. 133:2125-2130.

World Health Organization (2003) Fruit and vegetable promotion initiative. In: report of the meeting, Geneva, 2003

Yang Z, Chen Z, Yuan S, Zhai W, Piao X and Piao X (2009) Extraction and identification anthocyanin from purple corn (Zea mays L.). Int Food Sci \& Tech. 4:2485-2492.

Yang Z, Zhai W (2010) Identification and antioxidant activity of anthocyanins extracted from the seed and cob of purple corn (Zea mays L.). Innov Food Sci Emerg Tech. 11:169. 176 